\title{
Role of Melatonin as a Survival Factor for In vitro Development of Sheep Preantral Follicles
}

\author{
C. Chetan Kumar, B. Rambabu Naik, A.V.N. Siva Kumar, A. Ravi', \\ L.S.S. Varaprasad Reddy, Deepa Pathipati
}

10.18805/IJAR.B-4426

\begin{abstract}
Background: Melatonin, a powerful free radical scavenger and broad-spectrum antioxidant may directly affect ovarian function by regulating folliculogenesis, maintenance of follicular integrity, oocyte quality and maturation capacity. Therefore, we aimed to study effects of melatonin and its interaction with growth factors in sheep preantral follicles.

Methods: The influence of different concentrations of Melatonin (5-500 pM) on in vitro culture of preantral follicles (PFs') isolated from sheep ovaries was studied. Experiments I and II were conducted to standardize the optimum concentration of Melatonin that supports better development of preantral follicles. Experiment III was conducted with the optimum level of Melatonin derived in the Experiments I and II to evaluate the effect of melatonin at $100 \mathrm{pM}$ in combination with various growth factors.

Result: Overall follicular development was found to be the best in the PFs' cultured in medium supplemented with 100pM of Melatonin. Melatonin supplementation showed positive effects on the preantral follicular development in combination with different growth factors.

Key words: In vitro culture, Melatonin, Preantral follicles, Sheep.
\end{abstract}

\section{INTRODUCTION}

It was well established that mammalian preantral follicles do not grow in vitro as well as they do in in vivo (Arunakumari et al. 2010; Anil kumar et al. 2019). Two major reasons for such compromised development of preantral follicles are:1) Oxidative stress encountered during in vitro culture due to free radicals generated by endogenous process such as normal cellular metabolism and exogenous factors such as chemicals added to culture media, hyperoxia, exposure to light etc. (Natarajan et al. 2010) and 2) Frequent apoptosis of granulosa cells in culture. This indicates the need for presence of antioxidants in culture medium like Melatonin, a powerful free radical scavenger. Melatonin, a tryptophan containing hormone is synthesized predominantly in pineal gland, retina, gut and its production is also observed in the ovary in both cumulus cells and oocytes (Cassone et al. 1997; Soares et al. 2003). Earlier reports evidenced the presence of melatonin receptors in the ovarian follicular cells and follicular fluid (Soares et al. 2003) indicating the role of Melatonin in folliculogenesis (Taketani et al. 2011), oocyte quality and maturation capacity (Adriaens et al. 2006; Rodriguez et al. 2007) and maintenance of follicular integrity (Barros et al. 2013). Previous studies also indicated that melatonin was potentially useful in culture condition as it was a powerful free radical scavenger and a broad-spectrum antioxidant (Reiter et al. 2001; Nakamura et al. 2003; Tan et al. 2007) and it may directly affect ovarian function thereby serving as a local regulator in rats (Sakaguchi et al. 2013). Although existing information suggests that melatonin might control ovarian folliculogenesis, only meager reports are available indicating its direct role, especially on preantral follicles development to ovulatory stage in sheep. Accordingly the objective of the present study includes a)
Department of Veterinary Physiology, Sri Venkateswara Veterinary University, Tirupati-517 502, Andhra Pradesh, India.

${ }^{1}$ Department of Animal Nutrition, Sri Venkateswara Veterinary University, Tirupati-517 502, Andhra Pradesh, India.

Corresponding Author: A.V.N. Siva Kumar, Department of Veterinary Physiology, Sri Venkateswara Veterinary University, Tirupati-517 502, Andhra Pradesh, India. Email: priyamshiva@yahoo.com

How to cite this article: Kumar, C.C., Naik, B.R., Kumar, A.V.N.S., Ravi, A., Reddy, L.S.S.V. and Pathipati, D. (2021). Role of Melatonin as a Survival Factor for In vitro Development of Sheep Preantral Follicles. Indian Journal of Animal Research. DOI: 10.18805/IJAR.B-4426.

Submitted: 15-02-2021 Accepted: 21-05-2021 Online: 16-09-2021

Standardization of optimum concentration of Melatonin that supports better development of sheep PFs' in vitro and b) Interaction of Melatonin with other hormones and growth factors and their influence on in vitro growth of sheep PFs'.

\section{MATERIALS AND METHODS}

Unless otherwise stated, culture media, hormones, growth factors, FCS and all the other chemicals used in this study were purchased from Sigma Chemical Co. (St. Louis, MO, USA) and plastics from Nunclon (Roskilde, Denmark). All the methods described briefly hereunder are routinely employed in the culture of PFs' in the laboratory and described in detail in several earlier publication from the laboratory (Arunakumari et al. 2010; Kamalamma et al. 2016; Kona et al. 2016; Srividya et al. 2017; Anil kumar et al. 2019; Sravani pragna et al. 2020).

\section{Isolation of preantral follicles (PFs')}

A total of 175 ovaries and 790 preantral follicles collected on different days were used in this study. Ovaries recovered 
after sheep slaughter were transported to the laboratory within $1 \mathrm{~h}$ after slaughter in sterile, warm $\left(37^{\circ} \mathrm{C}\right)$ phosphate buffered saline.

Intact preantral (PFs') in the size range of 250-400 $\mu \mathrm{m}$ with intact basement membrane were mechanically isolated (Fig 1A) by micro dissection method from ovarian cortex under a stereo-zoom microscope (SMZ2T, Nikon corporation, Japan) and cultured them for six days (Fig 1B, 1C, 1D) according to the methods developed in our laboratory.

\section{Determination of optimum concentration of Melatonin for in vitro culture of Sheep PFs' (Experiments 1 and 2)}

Preantral follicles were cultured in bicarbonate buffered tissue culture medium 199 supplemented with $50 \mathrm{mg} / \mathrm{mL}$

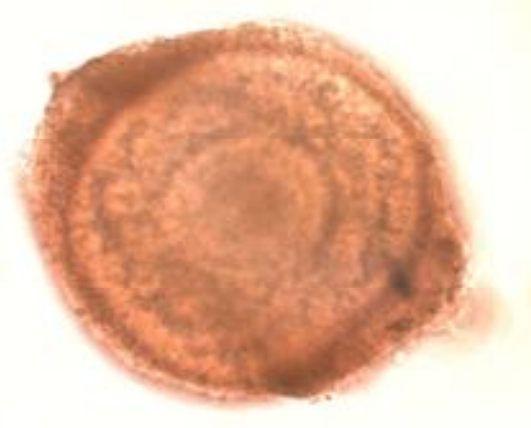

Fig 1A: Preantral follicle.

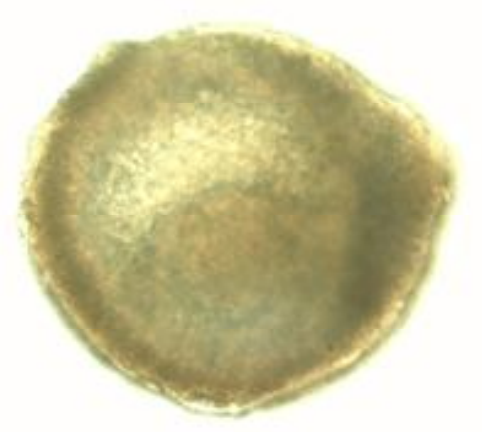

Fig 1C: Preantral follicle cultured for 4 days.

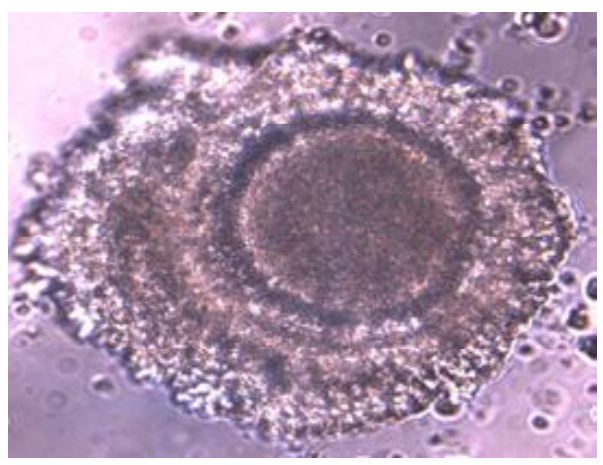

Fig 1E: Cumulus oocyte complex (COC) from 6 days cultured preantral follicle after subjecting to IVM for $24 \mathrm{~h}$.
Gentamycin sulfate (TCM 199B) and different concentrations of Melatonin (M 5250) chosen on the basis of the results obtained in earlier studies on IVM of mouse oocytes (Nabiuni et al. 2013). Two separate experiments with different ranges of concentrations of Melatonin (Experiment: 1- 0, 5, 10, 25, 50, 100, $500 \mathrm{pM}$ and Experiment: 2- 25, 50, 100, 250, 500 pM) were conducted.

\section{Evaluating the effect of Melatonin in combination with other growth factors and hormones (Experiment 3)}

To ascertain whether Melatonin supplementation to the culture medium encourage reasonable development and further improvement of cultured PFs' in sheep three differently supplemented media were used to culture the

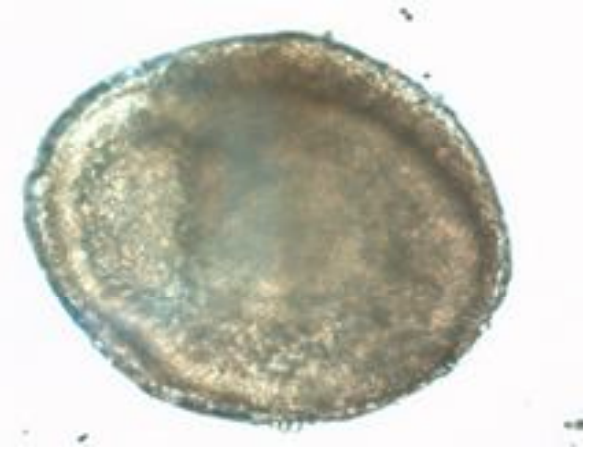

Fig 1B: Preantral follicle cultured for 2 days.

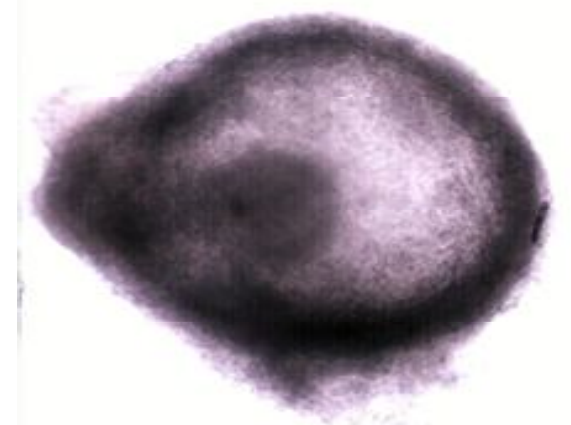

Fig 1D: Preantral follicle cultured for 6 days.

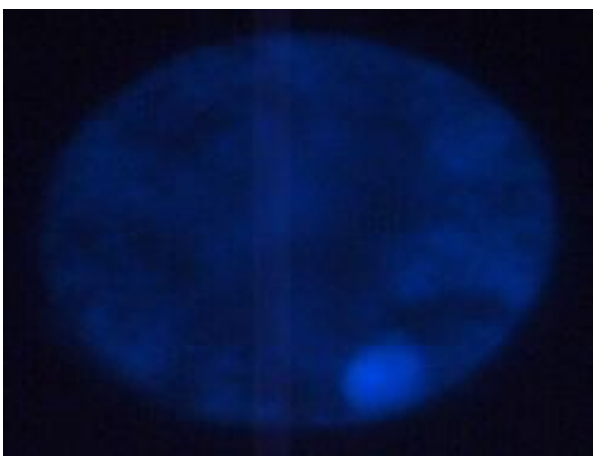

Fig 1F: M-II stage after IVM.

Fig 1A to 1F: Preantral follicle isolated from ovarian cortex $(1 \mathrm{~A})$ and subsequently exposed to culture medium for two days (1B), four days (1C), six days (1D), Oocytes of COCs from six day cultured follicles further subjected to IVM for 24h (1E) and Metaphase -II stage of oocyte from cultured preantral follicles after IVM (1F). 
PFs': (1) TCM 199 B medium containing $50 \mathrm{mg} / \mathrm{mL}$ gentamycin sulphate (control), (2) control medium supplemented with $1 \mathrm{mg} / \mathrm{mL}$ T4, $2.5 \mathrm{mg} / \mathrm{mL} \mathrm{FSH}, 10 \mathrm{ng} / \mathrm{mL}$ IGF-1, $1 \mathrm{mIU} / \mathrm{mL}$ of $\mathrm{GH}$ (Arunakumari et al. 2010) (referred to as the standard medium hereafter) and (3) standard medium supplemented with 100 pM of Melatonin (M 5250).

\section{Evaluation of growth and In vitro maturation of oocytes obtained from cultured PFs'}

The cultured PFs' were morphologically evaluated every $24 \mathrm{~h}$ for growth, increase in the diameter and antrum formation using an inverted microscope (Leica, DMIRB, Germany). The cumulus oocyte complexes from PFs' cultured for six days (Fig 1E) were further subjected to In vitro maturation for another $24 \mathrm{~h}$. Subsequently the oocytes were washed in Hoechst 33342 fluorescent stain solution (B 2261) and incubated in a $50 \mu \mathrm{l}$ droplet of the same solution for 15 minutes at $39^{\circ} \mathrm{C}$ (Rao et al.2002) which were examined under fluorescent light on an inverted microscope (Leica, Germany; excitation: 352-455nm and emission 460-490 nm) for $M$ II stage (Fig 1F).

\section{Statistical analysis}

The dependent variables are the development parameters of the follicles, and independent variables are the different treatments in the experiments. Comparison of the proportion of PFs' exhibiting growth, average increase in diameter, antrum formation and maturation to Mll stage of the oocytes from the in vitro cultured PFs' among different treatment groups were undertaken separately by one way ANOVA followed by Duncans multiple range test using SPSS 20 software.

\section{RESULTS AND DISCUSSION}

To our knowledge, this is the first study to address the influence of melatonin on in vitro development of preantral follicles. A total of seven hundred and ninety (790) preantral follicles were cultured in vitro in control, standard medium and melatonin treated groups. In experiment I, six different concentrations of melatonin $(5-500 \mathrm{pM})$ on in vitro development of PFs' were investigated individually and it appeared that melatonin at a concentration of $100 \mathrm{pM}$ favorably influenced the growth of PFs', average increase in diameter, exhibiting antrum formation and meiotic maturation percentage of oocytes to metaphase II from cultured PFs'. (Table 1). Previous studies by Shi et al. (2009) and El-Raey et al. (2011) support this observation wherein they indicated that higher levels of melatonin in the fluid of preovulatory follicles in porcine and bovine ovaries respectively might play an important role in process of ovulation. In contrast Ganji et al. (2015) reported that addition

Table 1: Effect of different concentrations of melatonin (0-500pM) on in vitro development of sheep preantral follicles.

\begin{tabular}{|c|c|c|c|c|}
\hline $\begin{array}{l}\text { Concentration of melatonin } \\
\text { (Replicates/ No of follicles) }\end{array}$ & $\begin{array}{c}\text { Proportion of PFs' } \\
\text { exhibiting growth } \\
\text { Mean } \pm \text { SE }\end{array}$ & $\begin{array}{c}\text { Average increase in } \\
\text { diameter }(\mu \mathrm{m}) \\
\text { Mean } \pm S E\end{array}$ & $\begin{array}{c}\text { Proportion of PFs' } \\
\text { exhibiting antrum } \\
\text { formation Mean } \pm S E\end{array}$ & $\begin{array}{r}\text { Proportion of PFs' } \\
\text { matured to Mll stage } \\
\text { Mean } \pm \text { SE }\end{array}$ \\
\hline \multicolumn{5}{|l|}{ Control (0pM) } \\
\hline TCM 199B (10/50) & $41.3 \pm 0.68^{b}$ & $14.3 \pm 1.18^{\mathrm{a}}$ & $22.5 \pm 0.93^{b}$ & $10.8+4.41^{a}$ \\
\hline $5 \mathrm{pM}(10 / 50)$ & $13.8 \pm 0.94^{\mathrm{ab}}$ & $8.5 \pm 0.66^{\mathrm{ab}}$ & $8.6 \pm 0.92^{\mathrm{ab}}$ & 0.00 \\
\hline 10pM (10/50) & $32.8 \pm 1.09^{\mathrm{ab}}$ & $8.3 \pm 1.53^{\mathrm{b}}$ & $17.8 \pm 0.99^{b}$ & 0.00 \\
\hline $25 \mathrm{pM}(10 / 50)$ & $42.3 \pm 1.12^{\mathrm{a}}$ & $12.3 \pm 0.77^{\mathrm{ab}}$ & $28.7 \pm 2.28^{\mathrm{a}}$ & 0.00 \\
\hline 50pM (10/50) & $60.1 \pm 0.88^{b}$ & $20.1 \pm 0.65^{\mathrm{ab}}$ & $28.7 \pm 2.28^{b}$ & 0.00 \\
\hline 100pM (10/50) & $69.6 \pm 5.17^{\mathrm{a}}$ & $21.6 \pm 0.92^{b}$ & $51.6 \pm 1.78^{\mathrm{ab}}$ & $21.47 \pm 3.54^{c}$ \\
\hline 500pM (10/50) & $29.2 \pm 1.49^{a}$ & $14.3 \pm 0.89^{b}$ & $40.5 \pm 1.81^{\mathrm{a}}$ & 0.00 \\
\hline Standard medium $(10 / 50)$ & $28.4 \pm 0.93^{a}$ & $8.9 \pm 0.82^{a}$ & $25.8 \pm 0.85^{\mathrm{ab}}$ & $14.6+8.43^{b}$ \\
\hline
\end{tabular}

Table 2: Effect of different concentrations of melatonin (25-500pM) on in vitro development of sheep preantral follicles.

\begin{tabular}{lcccc}
\hline $\begin{array}{l}\text { Concentration of melatonin } \\
\text { (Replicates/ No of follicles) }\end{array}$ & $\begin{array}{c}\text { Proportion of PFs' } \\
\text { exhibiting growth } \\
\text { Mean } \pm \text { SE }\end{array}$ & $\begin{array}{c}\text { Average increase in } \\
\text { diameter }(\mu \mathrm{m}) \\
\text { Mean } \pm \text { SE }\end{array}$ & $\begin{array}{c}\text { Proportion of PFs' } \\
\text { exhibiting antrum } \\
\text { formation Mean } \pm S E\end{array}$ & $\begin{array}{r}\text { Proportion of PFs' } \\
\text { matured to MII stage } \\
\text { Mean } \pm \text { S }\end{array}$ \\
\hline TCM 199 B (Control; 10/50) & $48.3 \pm 1.19^{\mathrm{ab}}$ & $6.4 \pm 0.718^{\mathrm{b}}$ & $34.5 \pm 5.24^{\mathrm{b}}$ & $10.1 \pm 3.5^{\mathrm{a}}$ \\
25pM (10/50) & $32.8 \pm 1.093^{\mathrm{a}}$ & $6.5 \pm 0.50^{\mathrm{a}}$ & $27.2 \pm 2.43^{\mathrm{ab}}$ & 0.00 \\
50pM (10/50) & $54.5 \pm 1.13^{\mathrm{a}}$ & $12.3 \pm 1.18^{\mathrm{ab}}$ & $43.8 \pm 3.51^{\mathrm{b}}$ & 0.00 \\
$100 \mathrm{pM}(10 / 50)$ & $65.3 \pm 1.07^{\mathrm{ab}}$ & $14.5 \pm 1.03^{\mathrm{ab}}$ & $55.5 \pm 2.16^{\mathrm{ab}}$ & $20.8 \pm 4.1^{\mathrm{b}}$ \\
250pM (10/50) & $41.2 \pm 1.94^{\mathrm{b}}$ & $8.5 \pm 0.77^{\mathrm{a}}$ & $35.5 \pm 4.04^{\mathrm{a}}$ & 0.00 \\
$500 \mathrm{pM}(10 / 50)$ & $41.2 \pm 1.94^{\mathrm{b}}$ & $10.2 \pm 0.89^{\mathrm{b}}$ & $34.9 \pm 5.31^{\mathrm{ab}}$ & 0.00 \\
\hline
\end{tabular}

Values (Mean \pm SE) with different superscripts within a column are significantly different. One way ANOVA followed by Duncan's Multiple Range Test $(\mathrm{P} \leq 0.05)$. 
Role of Melatonin as a Survival Factor for in Vitro Development of Sheep Preantral Follicles

Table 3: Effect of $100 \mathrm{pM}$ of melatonin in combination with standard medium on in vitro development of sheep preantral follicles

\begin{tabular}{lcccr}
\hline $\begin{array}{l}\text { Concentration of melatonin } \\
\text { (Replicates/ No of follicles) }\end{array}$ & $\begin{array}{c}\text { Proportion of PFs' } \\
\text { exhibiting growth } \\
\text { Mean } \pm \text { SE }\end{array}$ & $\begin{array}{c}\text { Average increase in } \\
\text { diameter }(\mu \mathrm{m}) \\
\text { Mean } \pm \text { SE }\end{array}$ & $\begin{array}{c}\text { Proportion of PFs' } \\
\text { exhibiting antrum } \\
\text { formation Mean } \pm \text { SE }\end{array}$ & $\begin{array}{r}\text { Proportion of PFs' } \\
\text { matured to MII stage } \\
\text { Mean } \pm \text { S }\end{array}$ \\
\hline TCM 199 B (Control 5/30) & $45.3 \pm 1.19^{\mathrm{b}}$ & $6.7 \pm 0.718^{\mathrm{a}}$ & $34.2 \pm 5.24^{\mathrm{b}}$ & $9.9 \pm 2.6^{\mathrm{a}}$ \\
Standard medium $(5 / 30)$ & $45.00 \pm 3.53^{\mathrm{b}}$ & $10.8 \pm 0.77^{\mathrm{b}}$ & $43.2 \pm 1.24^{\mathrm{b}}$ & $14.7 \pm 4.1^{\mathrm{b}}$ \\
Standard medium $+100 \mathrm{pM}$ & $79.6 \pm 6.44^{\mathrm{a}}$ & $12.6 \pm 1.87^{\mathrm{b}}$ & $58.8 \pm 2.81^{\mathrm{a}}$ & $22.6 \pm 2.4^{\mathrm{c}}$
\end{tabular}

of melatonin $(5 / 30)$

Values (Mean \pm SE) with different superscripts within a column are significantly different. One way ANOVA followed by Duncan's Multiple Range Test $(\mathrm{P} \leq 0.05)$.

of $100 \mathrm{pM}$ melatonin in the culture medium had negative effect on their survival, growth and diameter in mouse which might be due to species variation. The proportion of PFs' exhibiting growth and average increase in diameter was similar in the PFs' cultured in TCM199B supplemented with $50 \mathrm{pM}$ and 100pM but the proportion of PFs' exhibiting antrum formation was significantly greater at $100 \mathrm{pM}$ of Melatonin (Table 1). Although 25, 50 and $250 \mathrm{pM}$ of melatonin supplementation appeared to induce greater increase in growth, diameter and higher proportion of the follicles exhibiting antrum formation, it was not statistically significant. Therefore another experiment involving the concentrations of $25,50,100,250$ and 500pM was undertaken. However, even in experiment II, $100 \mathrm{pM}$ of melatonin supported the best development thereby confirming that this might be the optimum concentration for in vitro development of preantral follicles (Table 2).

In our study, among the melatonin treatments only the oocytes collected from preantral follicles cultured in $100 \mathrm{pM}$ of melatonin reached to MII stage and interestingly 5, 10, $25,50,250$ and $500 \mathrm{pM}$ concentrations of melatonin failed to support oocytes from cultured follicles to reach MII stage (Table 2). It may be speculated from previous studies that melatonin at $100 \mathrm{pM}$ could promote better expression of MT1 and MT2 receptors via c-AMP mediated signaling in the cumulus oocyte complexes or stimulation of maturation promoting factor of oocytes and in cumulus cells that positively affected the cytoplasmic and nuclear maturation (Soares et al. 2003; Chattoraj et al. 2005; El-Raey et al. 2011).

Further in Experiment III, 100pM concentration of melatonin was used in combination with growth factors and hormones to evaluate its action in inducing preantral follicular development with respect to parameters studied. While the average increase in diameter was similar in the PFs' cultured in standard medium and standard medium supplemented with 100pM of Melatonin, the proportion of PFs' exhibiting growth, antrum formation and meiotic maturation of oocytes to $M-I I$ were found to be significantly higher in standard medium supplemented with 100pM of Melatonin than in standard medium alone or in control medium (Table 3 ). It is remarkable to note that inclusion of melatonin (100pM) in the standard medium (i.e., TCM 199B supplemented with FSH, T4, IGF-I and GH) supported better development and also resulted in highest proportion of oocytes reaching $\mathrm{M}-\mathrm{II}$ from cultured follicles than in all other treatments. This could be due to the protective ability of melatonin on the cultured PFs' by modulating the growth factor expression (Schaeffer et al. 1997), up-regulating the anti-apoptotic genes (Fu et al. 2014) or by defending the oxidative damage to M-Il oocyte spindle (Banerjee et al. 2012), therefore, indicating the positive influence of melatonin when added in combination with growth factors on the follicular development as was reported earlier (Wang et al. 2013; He et al. 2016).

From this study we observed that melatonin supplementation at an optimum dose of $100 \mathrm{pM}$ significantly improved the in vitro development of sheep PFs' and the yield of fertilizable oocytes from cultured PFs'. Concomitant supplementation of melatonin in the standard medium supported better growth of cultured preantral follicles. Therefore, it is concluded that melatonin (100pM) acts as survival factor for in vitro development of preantral follicles in sheep.

\section{CONCLUSION}

From this study we observed that melatonin supplementation at an optimum dose of 100pM significantly improved the in vitro development of sheep PFs' and the yield of fertilizable oocytes from cultured PFs'. Concomitant supplementation of melatonin in the standard medium supported better growth of cultured preantral follicles. Therefore, it is concluded that melatonin (100pM) acts as survival factor for in vitro development of preantral follicles in sheep.

\section{ACKNOWLEDGEMENT}

The authors thank Sri Venkateswara Veterinary University (S.V.V.U), Tirupati for providing the chemicals and laboratory facilities to conduct this work.

\section{REFERENCES}

Adriaens, I., Jacquet, P., Cortvrindt, R., Janssen, K., Smitz, J. (2006). Melatonin has dose-dependent effects on folliculogenesis, oocyte maturation capacity and steroidogenesis. Toxicology. 228(2-3): 333-343.

Anil Kumar, P., Siva Kumar, A.V.N., Deepa, P., Praveen Chakravarthi, V., Brahmaiah, K.V., Rao, V.H. (2019). Leptin induced in vitro development of ovarian follicles in sheep is related to the expression of P450 aromatase and steroidiogenesis. Theriogenology 136: 1-6. 
Arunakumari, G., Shanmugasundaram, N., Rao, V.H. (2010). Development of morulae from the oocytes of cultured sheep preantral follicles. Theriogenology. 74: 884-894.

Banerjee, J., Maitra, D., Diamond, M.P., Abu Soud, H.M. (2012). Melatonin prevents hypochlorous acid induced alterations in microtubule and chromosomal structure in metaphase II mouse oocytes. Journal of Pineal Research. 53: 122128.

Barros, V.R., Cavalcante, A.Y., Macedo, T.J., Barberino, R.S., Lins, T.L., Gouveia, B.B. (2013). Immunolocalization of melatonin and follicle stimulating hormone receptors in caprine ovaries and their effects during in vitro development of isolated pre antral follicles. Reproduction in Domestic Animals. 48: 1025-1033.

Cassone, V.M., Natesan, A.K. (1997). Time and time again: the phylogeny of melatonin as a transducer of biological time. Journal of Biological Rhythms 12: 489-497.

Chattoraj, A., Bhattacharyya, S., Basu, D., Bhattacharya, S., Bhattacharya, S., Maitra, S.K. (2005). Melatonin accelerates maturation inducing hormone $(\mathrm{MIH})$ : induced oocyte maturation in carps. General and Comparative Endocrinology. 140: 145-155.

El Raey, M., Geshi, M., Somfai, T., Kaneda, M., Hirako, M., Abdel Ghaffar, A.E. (2011). Evidence of melatonin synthesis in the cumulus oocyte complexes and its role in enhancing oocyte maturation in vitro in cattle. Molecular Reproduction and Development. 78: 250-262.

Fu, Y., He, C.J., Ji, P.Y., Zhuo, Z.Y, Tian, X.Z, Wang, F. (2014). Effects of melatonin on the proliferation and apoptosis of sheep granulosa cells under thermal stress. International Journal of Molecular sciences. 15: 21090-21104.

Ganji, R., Nabiuni, M., Faraji, R. (2015). Development of mouse preantral follicle after in vitro culture in a medium containing melatonin. Cell Journal (Yakhteh). 16: 546.

He, Y., Deng, H., Jiang, Z., Li, Q., Shi, M., Chen, H., Han, Z. (2016). Effects of melatonin on follicular atresia and granulosa cell apoptosis in the porcine. Molecular Reproduction and Development. 83: 692-700.

Kamalamma, P., Kona, S.S.R., Praveen Chakravarthi, V.P., Siva kumar, A.V.N., Punyakumari, B., Rao, V.H. (2016). Effect of leptin on in vitro development of ovine preantral ovarian follicles. Theriogenology. 85: 224-229.

Kona, S.S.R., Praveen Chakravarthi, V.P., Siva kumar, A.V.N., Srividya, D., Padmaja, K., Rao, V.H. (2016). Quantitative expression patterns of GDF9 and BMP15 genes in sheep ovarian follicles grown in vivo or cultured in vitro. Theriogenology. 85: 315-322.

Nabiuni, M., Ganji, R., Bahadori, M. (2013). Melatonin Impact on In Vitro Development of Mouse Preantral Follicles and Oocyte Maturation. Anatomical Sciences Journal. 10:714.

Nakamura, Y., Tamura, H., Takayama., Kato H. (2003). Increased endogenous level of melatonin in preovulatory human follicles does not directly influence progesterone production. Fertility and Sterility. 80: 1012-1016. https:// doi.org/ 10.1016/S0015-0282(03)01008-2.
Natarajan, V.T., Singh, A., Kumar, A.A., Sharma, P., Kar, H.K., Marrot, L. (2010). Transcriptional upregulation of Nrf2dependent phase II detoxification genes in the involved epidermis of vitiligo vulgaris. Journal of Investigative Dermatology. 130: 2781-2789.

Pragna, K.S., Chakravarthi, V.P., Pathipati, D., Naik, B.R., Varaprasad Reddy, L.S.S., Kumari, B.P., Siva Kumar, A.V.N. (2020). Leptin Supplementation Stimulates Synergism with Growth Factors and Hormones to Express Its Receptor in Cultured Preantral Follicles of Sheep. Indian Journal of Animal Research. doi:10.18805/IJAR.B-4218.

Rao, B.S., Naidu, K.S., Amarnath, D., Vagdevi, R., Rao, A.S., Brahmaiah, K.V., Rao, V.H. (2002). In vitro maturation of sheep oocytes in different media during breeding and nonbreeding seasons. Small Ruminant Research. 43: 31-36.

Reiter, R.J., Tan, D.X, Manchester, L.C., Qi, W. (2001). Biochemical reactivity of melatonin with reactive oxygen and nitrogen species. Cell Biochemistry and Biophysics. 34: 237-256.

Rodriguez Osorio, N., Kim, I.J., Wang, H., Kaya, A., Memili E. (2007). Melatonin increases cleavage rate of porcine preimplantation embryos in vitro. Journal of Pineal Research 43: 283-288.

Sakaguchi, K., Itoh, M.T, Takahashi, N., Tarumi, W., Ishizuka B. (2013). The rat oocyte synthesises melatonin. Reproduction, Fertility and Development 25: 674-682.

Schaeffer, H.J., Sirotkin, A.V. (1997). Melatonin and serotonin regulate the release of insulin-like growth factor-I, oxytocin and progesterone by cultured human granulosa cells. Experimental and Clinical Endocrinology and Diabetes. 105: 109-112.

Shi, J.M., Tian, X.Z., Zhou, G.B., Wang, L., Gao, C., Zhu. S.E. (2009). Melatonin exists in porcine follicular fluid and improves in vitro maturation and parthenogenetic development of porcine oocytes. Journal of Pineal Research. 47: 318-323.

Soares, J.M., Masana, M.I., Erşahin, Ç., Dubocovich, M.L. (2003). Functional melatonin receptors in rat ovaries at various stages of the estrous cycle. Journal of Pharmacology and Experimental Therapeutics. 306: 694-702.

Srividya, D., Praveen Chakravarthi, V., Kona, S.S.R., Siva Kumar, A.V.N., Brahmaiah, K.V., Rao, V.H. (2017). Expression of kit ligand and insulin like growth factor binding protein 3 during in vivo or in vitro development of ovarian follicles in sheep. Reproduction in Domestic Animals. 52: 661-671.

Taketani, T., Tamura, H., Takasaki, A., Lee, L., Kizuka, F., Tamura, I. (2011). Protective role of melatonin in progesterone production by human luteal cells. Journal of Pineal Research. 51: 207-213.

Tan, D.X., Manchester, L.C., Terron, M.P., Flores, L.J and Reiter, R.J. (2007). One molecule, many derivatives: a never ending interaction of melatonin with reactive oxygen and nitrogen species. Journal of Pineal Research. 42: 28-42.

Wang, F., Tian, X., Zhang, L., Tan, D., Reiter, R.J and Liu, G. (2013). Melatonin promotes the in vitro development of pronuclear embryos and increases the efficiency of blastocyst implantation in murine. Journal of Pineal Research. 55: 267-274. 